\title{
Supplemental Tables and Figures
}

TABLE S1. Herbicide application rates at the two sampling sites

\begin{tabular}{|c|c|c|c|c|c|}
\hline \multirow[t]{3}{*}{ Herbicides } & \multicolumn{3}{|c|}{ Tolay Creek site } & \multicolumn{2}{|c|}{ Eel River site } \\
\hline & $11 / 23 / 1999^{a}$ & $11 / 13 / 2000$ & $11 / 27 / 2001$ & $11 / 2 / 1999$ & $11 / 20 / 2000$ \\
\hline & $\overline{(\mathrm{T} 1)}$ & (T2) & (T3) & $(\mathrm{E} 1)$ & $(\mathrm{E} 2)$ \\
\hline Oryzalin & $31.43^{b}(33.65)^{d}$ & $\mathrm{~N} / \mathrm{A}$ & $32.05(33.65)$ & $36.97(33.65)$ & $35.50(33.65)$ \\
\hline Isoxaben & $7.86(8.42)$ & $\mathrm{N} / \mathrm{A}$ & $4.40(4.21)$ & $9.32(8.42)$ & $4.46(4.21)$ \\
\hline Diuron & $N / A^{c}$ & $35.03(36.90)$ & $4.85(4.61)$ & $\mathrm{N} / \mathrm{A}$ & $\mathrm{N} / \mathrm{A}$ \\
\hline Clopyralid & $\mathrm{N} / \mathrm{A}$ & N/A & $1.05(1.05)$ & $\mathrm{N} / \mathrm{A}$ & $\mathrm{N} / \mathrm{A}$ \\
\hline Glyphosate & $6.32(5.61)$ & $\mathrm{N} / \mathrm{A}$ & $\mathrm{N} / \mathrm{A}$ & $4.93(5.61)$ & $14.17(16.83)$ \\
\hline
\end{tabular}

${ }^{\mathrm{a}}$ Herbicide application date; ${ }^{\mathrm{b}}$ application rate: $\mu \mathrm{g} / \mathrm{cm}^{2} ;{ }^{\mathrm{c}} \mathrm{N} / \mathrm{A}$ : not applicable; ${ }^{\mathrm{d}}$ Caltrans claimed rates 


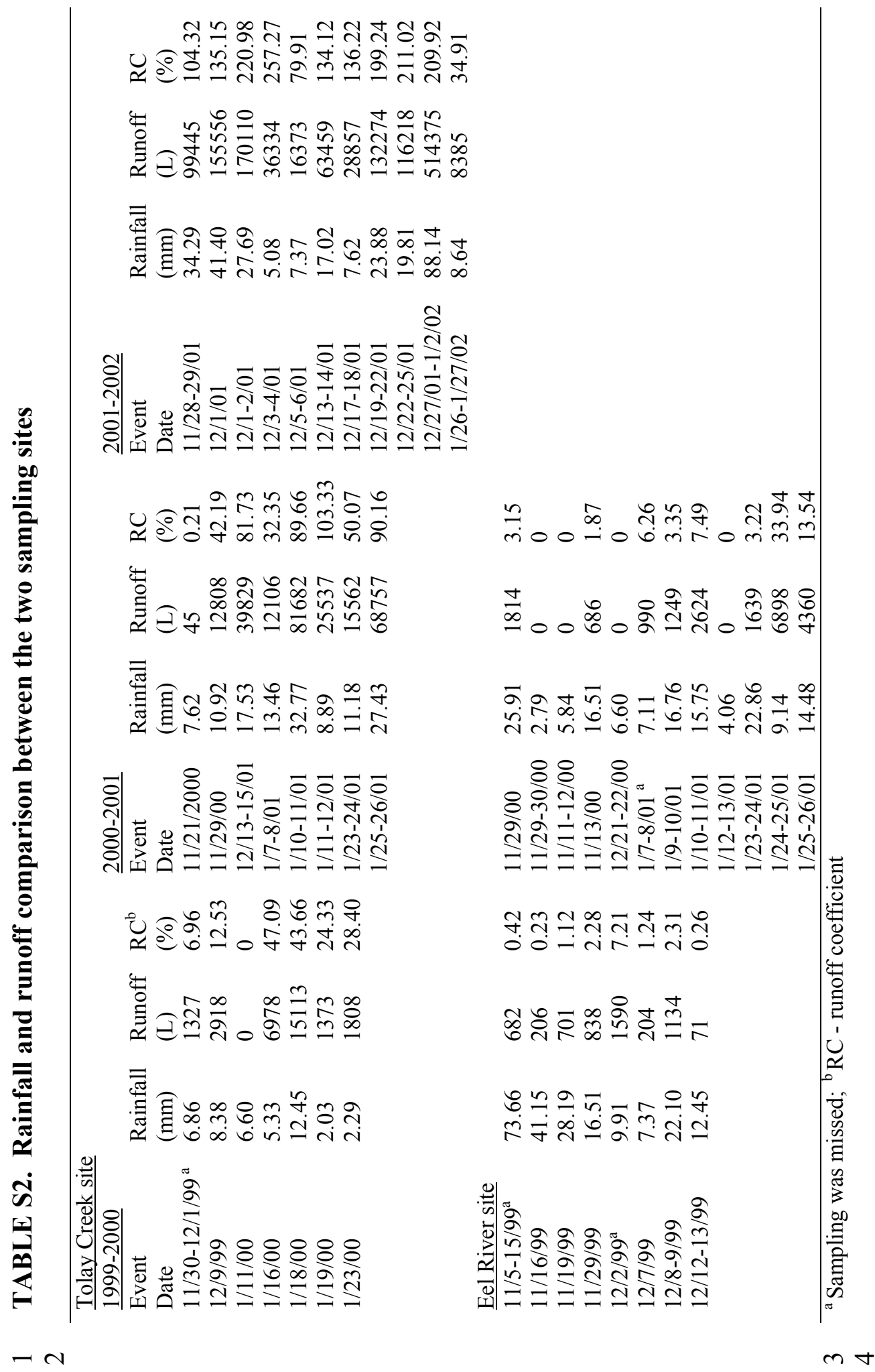




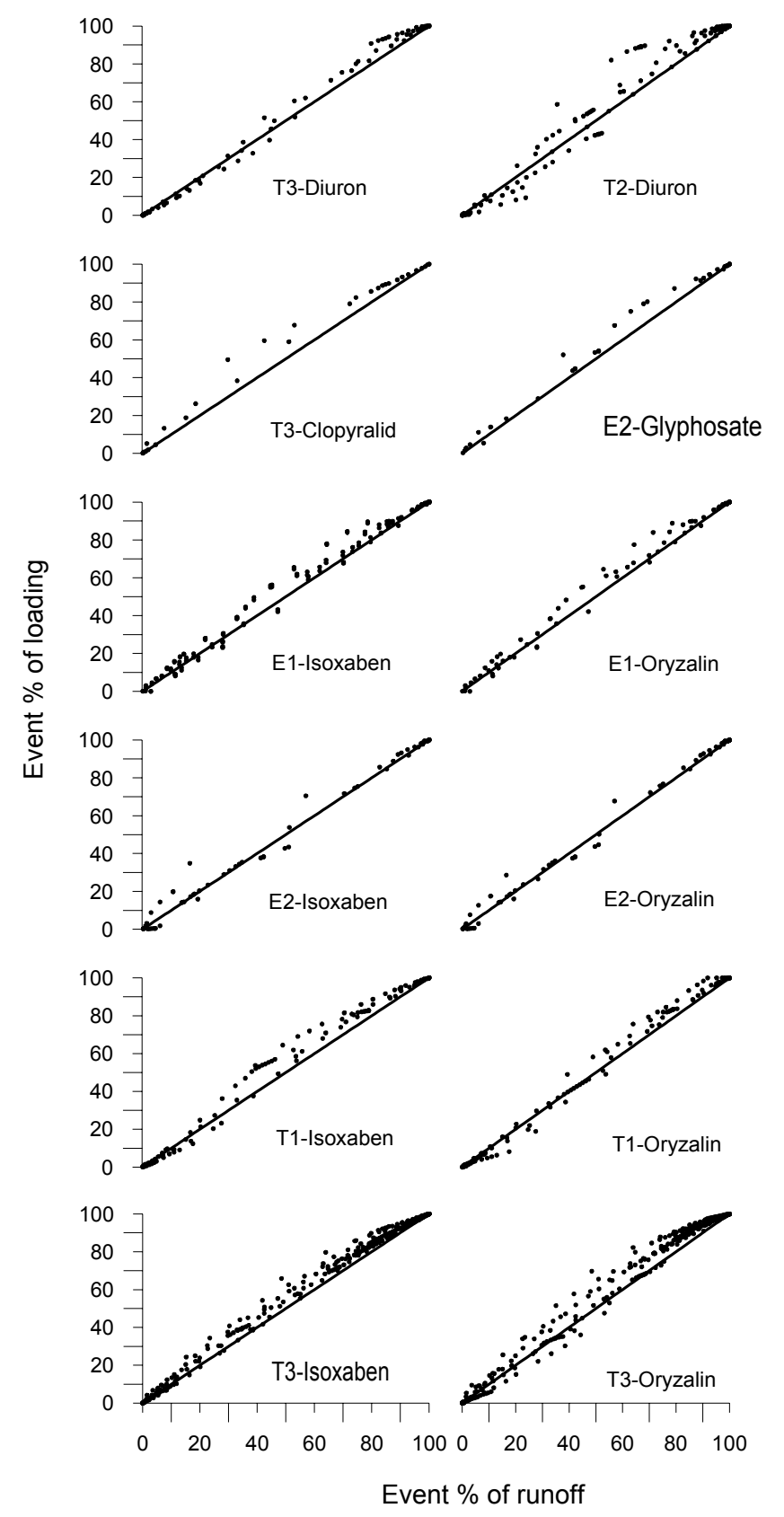

FIGURE S1. Event first-flush analysis. 


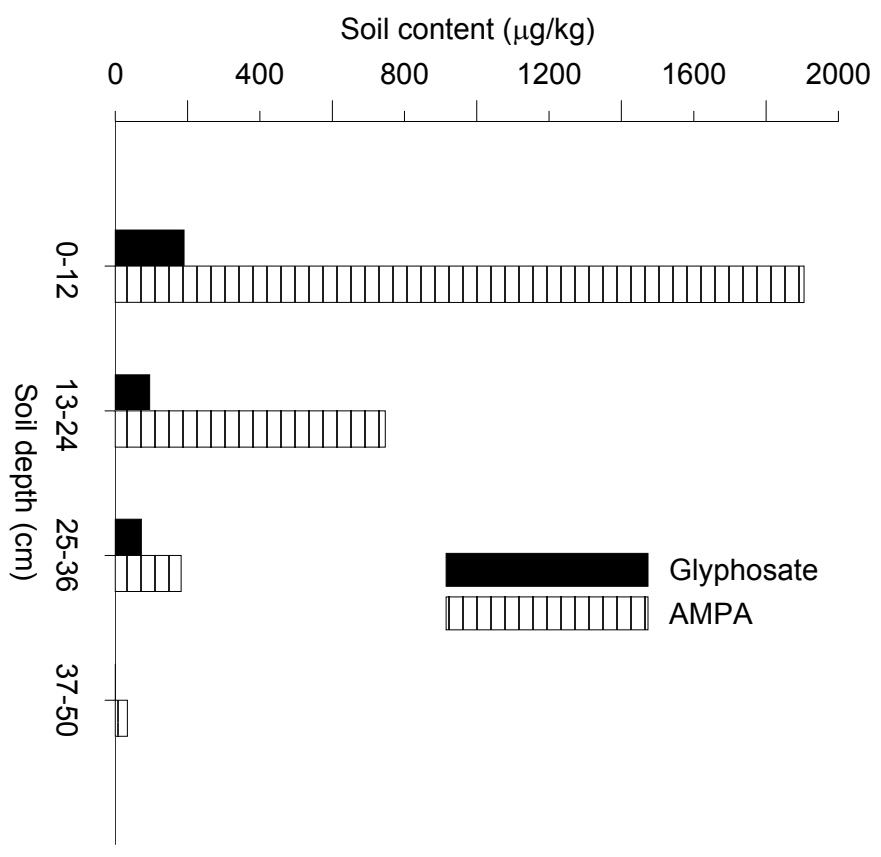

FIGURE S2. Vertical distribution of glyphosate and AMPA content within soil at the Eel River site during 2000-2001 (E2). 